\title{
Reduction of Odour Nuisance of Industrial Plants - Biofiltering in Composting Plants
}

\author{
Monika Gałwa-Widera ${ }^{*}$, Anna Kwarciak-Kozłowska', January Bień' \\ 1 Czestochowa University of Technology, Faculty of Infrastructure and Environment, Institute of Environmental \\ Engineering, ul. Brzeźnicka 60a, 42-200 Czestochowa, Poland \\ * Corresponding author's e-mail: mwidera@is.pcz.czest.pl
}

\begin{abstract}
Composting produces several hundred different substances. Among them, active fragrance compounds constitute a considerable number. Composting technology and the method of conducting the process are important elements. Due to the different ways of conducting the composting process, there are also areas of odour emissions as well as the volume of emissions. Depending on whether the process is conducted statically or dynamically, in a natural or artificial way and also in an open (e.g. field prism) or closed system (reactors, containers, encapsulated plots), the amount of odourant emitted will be uneven. One of the methods is the use of biofiltration. The biological filter for air purification is designed to remove volatile air pollutants leaving various installations. By using a suitable filter bed, total organic and inorganic carbon, sulfur and nitrogen compounds such as ammonia and hydrogen sulfide can be reduced. They are part of the odours that emerge, for example, from a composting plant. The use of biofilter eliminates polluting emissions, which in practice means reducing the negative impact on the environment and neutralizing odours. The article presents the results of biogas analysis generated in the composting process and ecological methods of removing odorants in the biofiltration process. Two types of filling were used to fill the biofilter. Both are fully biodegradable. It has been shown that these fillings have a high impact on the development of biofilm, and thus on the reduction of pollution.
\end{abstract}

Keywords: biomass, composting, industry, sewage sludge, odour

\section{INTRODUCTION}

The development of civilization is associated with the production of waste. A large part of waste is subjected to heat treatment, recycling, and biological processes. Unfortunately, all these processes also cause the formation of other types of pollution. The main reason for the complaints of the population on health and environmental quality are usually arising from odours. They are not only unpleasant, but also contribute to the development of anxiety about the state of health. Unfortunately, despite the high-performance technology of removing odour, the complaints of the population are not unfounded. All kinds of waste reprocessing plants still represent an environmental problem. The provisions concerning the emission limit do not specify the obligation to reduce the emission of odourants [Kośmider
2002]. Odour pollution, however, shows the presence of substances referred to in the Regulation of the Minister of Environment of 26th January 2010 [Rozporządzenie Ministra Środowiska 2012].

Of course, not only the waste reprocessing plants, such as composting plants, sewage treatment plants or landfills, generate odour. This group also includes other branches such as animal breeding farms or processing plants, refineries [Rozporządzenie Ministra Środowiska 2012]. The compounds that are characterized by odour nuisance are mainly hydrogen sulfide, ammonia, sulfides and volatile organic compounds. According to the literature data, there are more than 100 of these compounds [Kwarciak-Kozłowska 2014].

The aim of the research is to optimize the process. The research described in the article included the stage of selection of biofilter filling. The authors focused on two fillings selected from 
among several analyzed in the laboratory taking into account porosity, nutrient content, availability, price and degradability. The aim of the research was first of all to check the effectiveness of the biofiltration process on a technical scale [Van Groenestjin 2005].

\section{METHODS USED FOR DEODOURIZATION OF GASES}

Total elimination of odourant emissions into the atmosphere seems impossible. This is due to the fact those are released during many technological processes.

Various stages such as unloading, transshipment or transport also form part of the technology, and it is not always possible to resign from them. For many gases, which are characterized by unpleasant odour, the sensing threshold is very low. Therefore, their complete removal from waste gases, should be taken into account at the design stage [Twardowski 2000, Warych 1998].

Deodourization methods can be basically divided into two groups. A group of chemical methods includes oxidation, chlorination, disposal of thermal as well as the methods using catalytic and sorptive processes. The second group includes, greener biological methods, such as biological MUDs called scrubbers or the methods based on natural materials and micro-organisms. The biological MUDs use activated sludge as a filtering layer, which constitutes a suspension of microorganisms in the water. On the other hand, filtration uses heterotrophic activity aerobic bacteria. Microorganisms have the ability to conduct the process of purifying the sorbent in an aerated chamber. After such treatment, a stream returns to the scrubber. Packed filters are characterized by slightly different design . Here, the main element is a layer filter material with high porosity. Living micro-organisms, capable of biological decomposition of impurities contained in the air, deposit themselves on such filters. The process is run by the transmission method (blowing out) of contaminated gases through the deposit, followed by two types of processes: sorption filtration and biological pollutant distribution in which the active micro-organism flourish. This method, as in the case of the scrubber, is is susceptible to selfhealing. Last year shows that biological methods are effective for the disposal of volatile contaminants, both those associated with the formation of odours and volatile organic compounds such as chemical or physical methods [Dicks 1991].

When a contaminated gas flows through a layer of filter material, a diffusion of impurities from the gas phase to an active biological layer, surrounding the particle filter material, occurs [Warych 1998]. Consequently, the growth of microorganisms on the biomass "handles" a greater amount of pollutants.

The process of mineralization of pollutants in biofilter is possible thanks to the bacteria, fungi and thermophilic Actinomycetes forming on the surface of the sorbent active biofilm.

A biofilter, depending on the process parameters can be of varying size and shape. The way of supplying air also differs, as it is dependent on the spatial capabilities and scale. Large containers with height of up to several meters are used most often. Examples of such biofilters are illustrated in Figure 1.

The air supply to the layer of the deposit may also be diverse. One of the methods is to push air through the slotted chambers directly from shots or gas through the humidifier, as presented in Figures 2 and 3 [van Groenesjin 2005].

In the first case, a system of perforated pipes, placed in a layer of gravel is implemented - its task is to facilitate even distribution of gas in the biofilter. In the second case slotted Chambers may be used, as they are a durable design.

In the case of a large load of dirt, one can apply a storied building, i.e. a couple of biofilters placed one above the other. In addition, the Strip subjected to biofiltration process should be moistened for a relative humidity of $95-100 \%$. In this situation, it is perfect to bring water vapour (steam with a humidifier) to the stream of gases.

The phenomenon of condensation often occurs in the biofilter. The condensate can be used to spray deposits on the filter. This is an effective solution to ensure that the installation will work on waste without wastewater. This includes the sealed biofilters. In the case of biofilters and open drains, the humidity of the biomass depends on various atmospheric conditions.

\section{MATERIAL AND METHODS}

The study had a trial basis. The analysis focuses mainly on the elimination of odours of inorganic origin such as hydrogen sulphide and ammonia. The scope of the research included the 


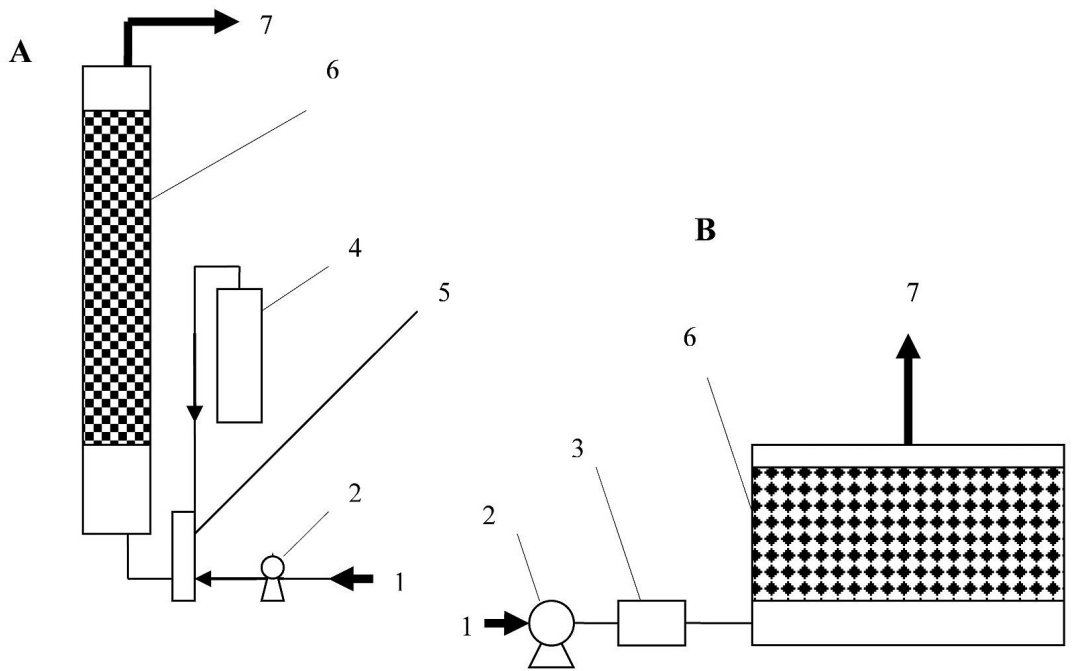

Fig. 1. Wiring diagrams for deodourization of gases: A - installation of the column, B - installation of the container, 1 - supply of contaminated gas, 2 - pressure-suction, 3 - humidification chamber, 4 - steam tank,

5 - mixing, 6 -biologically active deposits, 7 - the outflow of the purified gas) [Wierzbińska 2015]

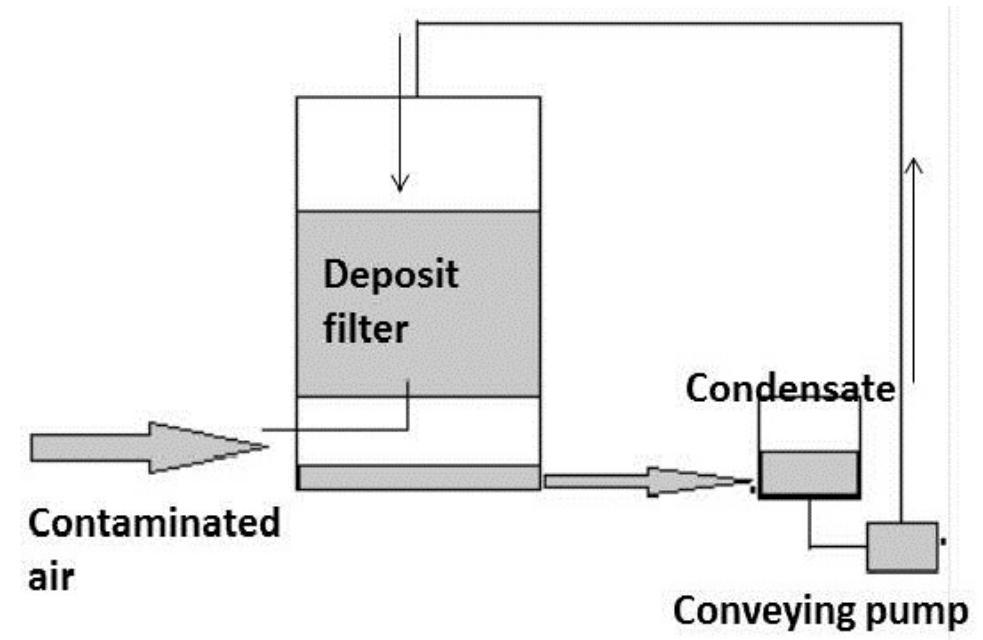

Figure 2. Diagram of biogas supply to the deposits without humidification

analysis of biogas suction from a reactor that carried out the composting process. The scale of the research was defined as half-technical. The experiment was carried out using two types of filling, i.e. peat and sawdust.

The composting process itself occurred in a commercial composting plant running on "MUT", container, consisting of 6 containers with one control unit. Each container was filled in $3 / 4$. The capacity of a single unit was $25 \mathrm{~m}^{3}$. The system was capable of monitoring temperature, humidity, $\mathrm{pH}$, and forced aeration.

A mixture of compost kitchen waste and the organic fraction of municipal waste were investigated. The process was carried out for 5 weeks. The parameters of composting were determined: moisture content of the mixture - 50-60\%, $\mathrm{pH}-6-7$, the level of aeration $-4 \mathrm{dm}^{3} / \mathrm{min}$.

All parameters of the composting process were maintained in accordance with guidelines on the processes of composting, fermentation and mechanical-biological treatment of waste by Ministry of Environment. A biofilter was installed on the bioreactor.

The research was carried out on the microorganisms adapted to the distribution of the contaminants on the fill layer inside the biofilter casing. The volume of the biofilter was $2 \mathrm{~m}^{3}$. The biofilter has to be active for a certain amount of time before the biofilm with microorganisms flourishes on it. The experiment uses the settling of the deposits commercially. 


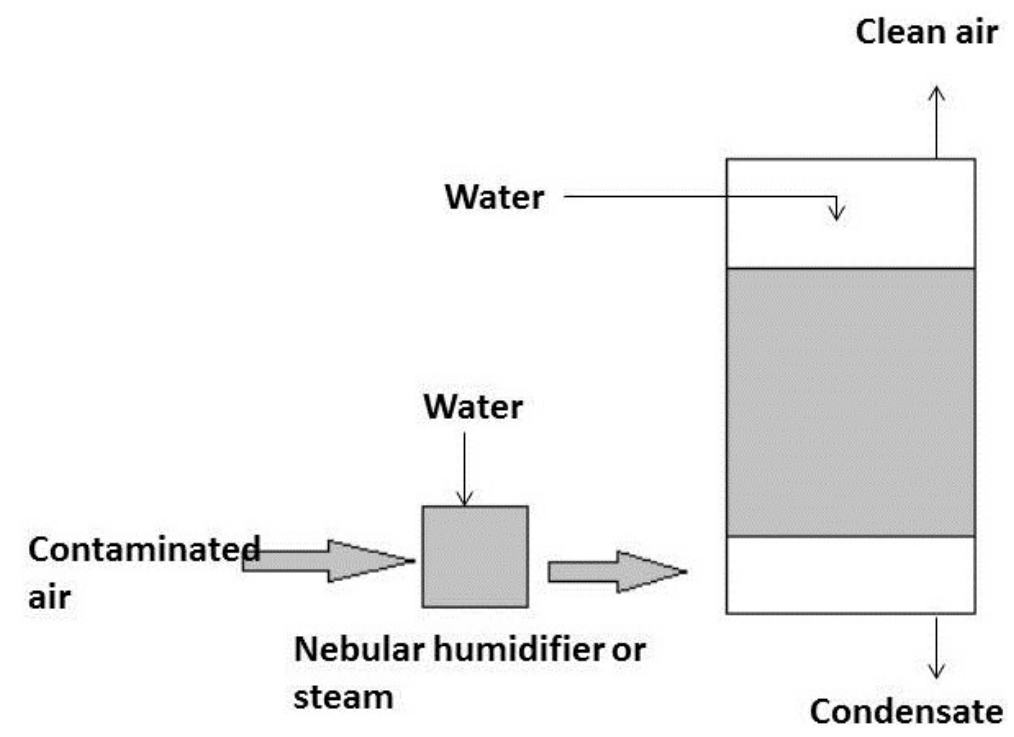

Figure 3. Diagram of biogas supply to the deposits by the installation of the steam humidification

The contaminated gases were carried out laterally in accordance with the circuit diagram (Figure 4).

The experiment uses a layout without humidification. In the solution, there is a possibility that the condensate accumulated on the walls of the biofilter returns. It may be re-used for spraying. This makes the installation work without waste water discharge, and is followed by a sprinkling of filling and microorganisms that colonize in the leachate in addition to deposit.

The analysis of power consumption of biogas is made directly from the reactor and after biofiltration.

The analysis uses the portable biogas Analyzer series 5000 GA certified ATEX II $2 \mathrm{~g}$ Ex ib IIA $\mathrm{T} 1 \mathrm{~Gb}\left(\mathrm{Ta}=-10^{\circ} \mathrm{C}\right.$ to $\left.+50^{\circ} \mathrm{C}\right)$, IECEx, CSA.

\section{RESULTS AND CONCLUSIONS}

Biofiltration represents a highly complex process that is carried out in the liquid phase and gas and its effect is the formation of biodegradable products: $\mathrm{CO}_{2}, \mathrm{H}_{2} \mathrm{O}$ and other inorganic compounds. The odour pollution contained in flowing air becomes liquid adsorption on the surface of the biofilm covering the particles of the filter material. The odour particles adsorbed on the surface of the biolayer, pass to the liquid phase and undergo diffusion towards the micro-organisms, induced by biofilm.

The process that takes place on the surface of the biofilter particles consists in the distribution of contaminants and is called "biodegradable". Biodegradation takes place in two stages. The

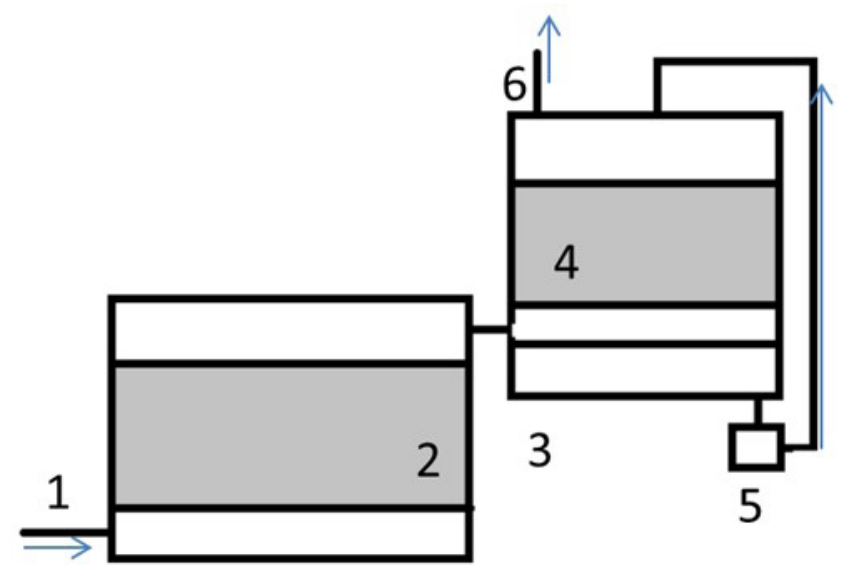

Figure 4. Layout scheme used in experiment 1 - air inlet, 2 - reactor-reaction containers set, 3 - biofilter, 4 - deposit , 5 - effluent of the condensate, 6 - clean air 
first step is biosorption, which consists of stopping the pollution on the surface of cells.

The surface of the cell is the site of the Exchange, subject to the diffusion components to the Interior of the cell as well as the excretion of waste products and enzymes decomposing matter outside the cell in the opposite direction. The second stage of biodegradation is mineralisation.

It involves assisting the breakdown of organic compounds by micro-organisms, using energy and biogenic elements and expelling simple mineral products. Distribution of organic molecules occurs generally within the cell. Macromolecular compounds, such as proteins, cellulose, or other natural and synthetic polymers, are hydrolyzed outside the cell. The Interior of the system products of this diffusion were subject to oxidation. These changes occur under aerobic conditions [Pawlaczyk-Szpilowa 1980]. The fundamental mechanisms in the process of biofiltration, consisting in the kinetics of the removal process of impurities from gases are-sorption and their biodegradation [Adler 2001].

The result of the distribution of biological biolayer is the absorption of pollutants on the surface of the biofilm. The self-cleaning of gas treatment using biofilters and sorbent technology and is virtually waste-free [Szklarczyk 1991, Szynkowska 2010].

The filter material should be regarded as the most favourable condition for the development of micro-organisms in order to obtain the maximum of biodegradable pollutants. In this case, the two types of material are applied. Both of these materials have proven to be effective in the filtration process. However, better results in the formation of biofilms were obtained in the case of peat. It was found on the basis of random microbial analysis. Plating method was executed on enriched agar incubated for $48 \mathrm{~h}$ at temperatures of $20^{\circ}$ and $37^{\circ}$; it was stated that in the case of peat plate, moved the micro-organisms in majority. The porosity of the deposit, that is, the size and distribution of grains and pore structure must provide high surface activity at low pressure of gas (large specific surface area, loose structure, low gas flow resistance). In this case, peat was also characterized by better parameters; better maintained moisture levels, not "settled" in the course of the process as much as in the case of sawdust. Fresh (raw) filter material should have a $\mathrm{pH}$ of $7-8$, the volume of pores above $90 \%$, grain diameter larger than $4 \mathrm{~mm}$. It should contain over $55 \%$ of organic material [Szklarczyk 1991]. These conditions are definitely better with peat filling.
In accordance with the research and literature, organic materials good biological filters. These include: fertile soil of loosened structure, peat and peat waste composts made from the bark of trees, wood waste, and composts from municipal waste [Jorio 2000].

In nature, there is a great variety of heterotrophic bacteria, mostly located in the soil and water, having the ability of absorbing organic matter; these bacteria are involved in important processes of purification and regeneration of the environment.

Many of these bacteria have the ability to break down organic substances, uncommon in the wild nature, such as industrial waste [Szklarczyk 1996, Ulfik 2010].

Micro-organisms are very easy to adapt to the distribution of pollutants containing alcohols, ketones, and esters. Compost usually contains sufficient number and variety of micro-organisms capable of complex biochemical decomposition of pollutants.

At the same time, the micro-organisms show a great ability of adapting to specific pollutants contained in the waste gases. In the experiment, the waste gases ran through the entire technological line; therefore, there is a high probability the partial purification of gases occurred during blowing by the compost mass. Hence, a significant drop in pollution along with the progress of the humification process was observed.

The experiment involved the intentional introduction of seeding consisting of a mixture of micro-organisms and nutrient solution. The aim was to speed up the creation of the biofilm and increase the number of micro-organisms. Owing to such treatment, very good results related to the removal of most hydrocarbons from the industrial gases are achieved [Szklarczyk 1996, Wierzbińska 2015].

Technological reasons for the correct operation of the biofilter are important parameters such as: contact time gas deposit, deposit load, porosity and specific surface area, the flow resistance. Retention time of the gas in the biofilter is dependent on the type of contamination and their solubility in water. It should be long enough to absorb the aqueous layer of biofilter's pollution, and thus become available for the biodegradation of micro-organisms [Sówka 2011, Kapusta 2007].

The performance of the biofiltration process also affects the physical and chemical conditions found in a fluid. They have an impact on the health and the quantity of the micro-organ- 
isms responsible for the process gas. Therefore, it is important to provide the optimal environment for their development. The effects of the impact of a given factor may be different depending on its type and intensity, as well as the quality of the body. The most important factors that affect growth, reproduction, survival and metabolic activity of microorganisms include: temperature, concentration of hydrogen ions, oxy-reduction potential, water content in the environment, the availability of food and harmful chemicals. Temperature has a direct impact on the life processes of micro-organisms. Therefore, it is one of the most important factors determining the growth rate, enzyme activity or the chemical composition of cells and nutritional requirements. It can also indirectly influence the solubility of the compound molecules, intracellular transport of ions and the diffusion of the chemicals as well as the characteristics of osmotic membranes. The optimum temperature is $25-40^{\circ} \mathrm{C}$. In the case of different micro-organisms, the quality of the treated gas, the type of compounds should be taken into account so as to optimize the temperature of the deposit and obtain the highest efficiency. Due to the microbiological activity, large amounts of heat may be released, raising the temperature in the filter deposits.

In winter, the temperature inside the biofilter may be higher than the ambient temperature $10-20^{\circ} \mathrm{C}$ [Brugess 2001, Adamiak 2012, Wierzbińska 2010]. An equally important factor, not only on the viability of organisms, but also absorption from the gas phase contaminants, is humidity. The bacteria are generally extremely resistant to desiccation, but it can cause deterioration of the effects of biofiltration by gradually slowing down, or even halting the processes of metabolism. Furthermore, in a dry deposit, the area of direct contact is decreased, and this in turn reduces the efficiency of the biofilter operation. Therefore, the gas can be pre-humidified before entering the filter deposit. Not every process requires such a procedure, but it is beneficial to prepare a system so that this option can be used. Of course, the excess water is also not advisable. The microorganisms inhabiting the deposit are heterotrophic aerobic organisms, and the excess moisture may lead to the formation of anaerobic areas, causing decay, which also deteriorates the deodourization effects [Adamiak 2012, GałwaWidera 2016]. The activity of microbial life is heavily dependent on the concentration of hydrogen ions. Their level is determined by the nu- merical value $(\mathrm{pH})$. The optimal $\mathrm{pH}$ is neutral, but the biofilter process gas containing, for example hydrogen sulfide may cause acidification of the substrate, which leading to a reduction of bacterial activity. The reaction of the deposit should be adjusted, for example, by means of calcium carbonate in neutralizing acids, or by using microscopic fungi in the biofilter, because they are more resistant to the changes in $\mathrm{pH}$ than bacteria [Ramirez 2012, Adamiak 2012, McNevin 2000, Ulfik 2010]. As is clear from the analyses, the $\mathrm{pH}$ prevailing in the deposit was maintained as neutral. Important factors in the inhibition of vital micro-organisms are different poison types. The detrimental effect for the organism depends on the type of toxins, as well as the dose. The substances harmful to microorganisms are: heavy metals, detergents, cyanides, pesticides, strong oxidants. They damage the cell membranes of bacteria and result in denaturation of proteins or enzymes inhibition. However, all bacteria and living organisms are resistant to environmental factors, and they are able to increase the resistance through adaptive processes. The parameters of the composting process while using biofiltration for deposits of solid odourants are specified for both the mixture of compost and filter deposit (Table 1).

In the biomass rich in nutrients, microbial growth occurs, which in effect, "converts" a larger amount of impurities. Bacteria and actinomycetes, as well as fungi and myco-trophic algae such as green algae are primarily involved in the mineralization of organic pollutants,. The result of biodegradation of absorbed impurities in the biolayer is self-healing filter material, covered with a biofilm. This self-cleaning sorbent makes gas treatment using a biofilter a virtually wastefree process.

Each bacterial species grows in a specified temperature range. It should be assumed that the optimal temperature range in the biofilter is $25-33^{\circ} \mathrm{C}$. In winter, the temperature inside the biofilter is higher than the ambient temperature,

Table 1. Parameters of the process biofiltration air containing odourants, created during composting

\begin{tabular}{|l|c|}
\hline \multicolumn{1}{|c|}{ Parameter } & Value \\
\hline $\mathrm{pH}$ compost mixture & $5,8-7,5$ \\
\hline $\mathrm{pH}$ filter media & $6-7$ \\
\hline $\begin{array}{l}\text { Relative humidity mixture of } \\
\text { compost }\end{array}$ & $45 \%-60 \%$ \\
\hline Relative humidity filter media & $50 \%-60 \%$ \\
\hline $\mathrm{C} / \mathrm{N}$ (compost mixture) & $2-30: 1$ \\
\hline
\end{tabular}


ranging from 10 to $20^{\circ} \mathrm{C}$. This is because the large amounts of heat are released in the microbiological processes. Moreover, a process of composting is involved, which generates heat, especially in the first 14 days. Through this process, the air discharged from the reactor goes to the biofilter already in the heated form. A significant increase in the temperature in the dynamic phase of the composting process starts relatively early (Figure 4).

For most bacteria, the optimum $\mathrm{pH}$ value is 7.0-7.5. A drop in $\mathrm{pH}$ below 4 and an increase over 11, results in a significant reduction of the bacterial activity, as well as frequent and extreme changes in the environmental $\mathrm{pH}$ (Table 1). It is therefore important to maintain proper humidity and $\mathrm{pH}$ in the reservoir. The wetting process was conducted by recycling the condensate and putting it in an aerosol form. The air flow was regulated. Some species have the ability to actively influence the external $\mathrm{pH}$ and change them to favourable values.

The use of biofilters in composting of municipal waste allows the removal of almost all of specific pollutants characterized by odour nuisance.

The filtering material used in the process included sawdust and peat. The gas analysis con-

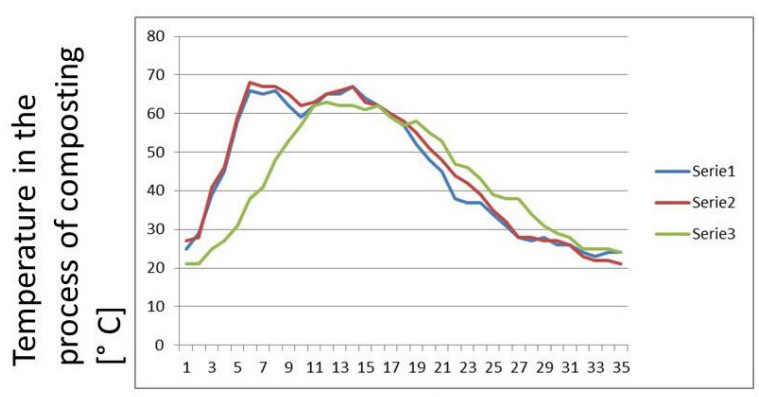

day the process

Figure 5. Figure temperature changes in the process of composting ducted before and after filtration demonstrated that a more efficient removal of odourous compounds occurs with peat-filled biofilter.

A significant decrease in the content of gaseous pollutants produced in the composting process may be noted. Clearly better results were obtained using a peat deposit (Table 2).

This is due to increased porosity and thus greater space inhabited by microorganisms. The lower layer of the biofilter was filled with coarse filter material in the form of wooden frameworks. This was the first stage of purified biogas adaptation. The quality of the filter material also has an impact on the development of the biofilter. Seed analysis showed that the surface of peat developing biofilm faster than in the case of sawdust. The biodiversity of nutrients contained in the peat had a positive effect on the rate of settlement deposits. The method consists in the biological oxidation of $\mathrm{H}_{2} \mathrm{~S}$ to elemental sulfur by a specialized group of microorganisms from the family Thiobacillus, according to the reaction:

$$
2 \mathrm{H}_{2} \mathrm{~S} 2 \mathrm{~S}+\mathrm{O}_{2}+2 \mathrm{H}_{2} \mathrm{O}
$$

They use a carbon dioxide as a carbon source. The product transformation is elemental sulfur and sulphates. The ammonia principle works by inhibiting the development of micro-organisms. The purpose of nitrifying bacteria is to provide a nitrogen source for the microorganisms.

Studies show that the use of biofiltration in technological processes is associated with a number of benefits. At the same time, this method is simple and does not require the application of excessive financial outlays. The odour is not only hydrogen sulfide and ammonia tests involve further analysis and selecting the bed for a process optimization. Time biogas flow through the fixed bed was forced air.

Table 2. Changes in the concentration of hydrogen sulfide and ammonia using a biofilter with peat and sawdust fillings

\begin{tabular}{|l|c|c|c|}
\hline \multicolumn{1}{|c|}{ Contamination } & $\begin{array}{c}\text { Concentration } \\
\text { before biofilter } \mathrm{mg} / \mathrm{m}^{3}\end{array}$ & $\begin{array}{c}\text { Concentration } \\
\text { after biofilter } \mathrm{mg} / \mathrm{m}^{3}\end{array}$ & Removal efficiency, \% \\
\hline \multicolumn{4}{|c|}{ The results obtained for deposits of peat* } \\
\hline Hydrogen sulfide & 3670 & 37 & 99 \\
\hline Amonnia & 560 & 44 & 84 \\
\hline \multicolumn{4}{|c|}{ The results obtained for deposits of sawdust } \\
\hline Hydrogen sulfide & 3588 & 180 & 95 \\
\hline Amonnia & 570 & 80 & 86 \\
\hline
\end{tabular}

* The results of the tests present the arithmetic mean of three experiments, due to the long-term nature of the process and the scale of the sample. 


\section{CONCLUSION}

Composting facilities are potential sources of odour nuisance but they can be effectively reduced through encapsulation devices and the use of deodourization methods. The biological methods, and in particular biofiltration, are increasingly popular due to their simplicity as well as low investment and operating costs, while being able to obtain high efficiency of treatment. However, proper selection of the device parameters (dimensions, layer height of the deposit, the appropriate distribution of treated gases) and proper operation, ensuring their smooth operation are important.

Biological methods, including biofiltration, are commonly used in the deodourization processes of gases, particularly in municipal buildings (sewage treatment plants, landfills). The conducted research indicates that biofiltration is an effective method of flue gas cleaning. The resulting gas purification efficiency, depending on the substances contained therein, ranges from 40 to $100 \%$. An important issue related to the proper functioning of the biofilter, in addition to the use of appropriate design solutions, pre-treatment and conditioning of gases, is to provide optimal conditions for the growth and degradational activity of microorganisms. Providing certain regimes, concerning, among others temperature or humidity, affects the stable operation of the biofilter and increases the efficiency of gas purification related to odour-generating compounds.

Studies have shown that both fillings meet the criteria for the substrate to produce a biofilm. The effectiveness of odour removal in the case of peat and sawdust deposit is characterized by the appropriate parameters $(\mathrm{pH}$, humidity, porosity) to reduce pollution by over $80 \%$. According to the authors, the peat filling shows a reduction to a smaller extent but makes maintaining stable conditions for microorganisms easier. The main factor is that the peat maintains a constant humidity. During the experiments, it was also noticed that a significant increase in the biofilm appeared in the thermophilic phase of composting. It consisted of such factors as the higher content of nitrogen and sulfur compounds and the higher gas temperature at the entrance to the biofilter. A further part of the research will be conducted in the direction of determining the impact of the results obtained on other volatile pollutants.

\section{Acknowledgement}

Accomplished with BS/PB-401-301/11 request 6 .

\section{REFERENCES}

1. Adamiak W., Kita U., Sówka I., Szklarczyk M., 2012. The role of microbial selection in the benzene biodegradation process, Chemical Industry, 91(5), 655-659.

2. Adler S.F. Use these guidelines to scale up and design biofiltration processes for the control of volatile organic compounds. CEP, 2001.

3. Burgess J.E., Parson S.A., Stuetz R.M., 2001. Developments in odour control and waste gas treatment biotechnology: a review, Biotechnology Advances, 19, 35-63.

4. Dicks R.M.M., Ottengraf S.P.P. 1991. Verification studies of a simplified model for the removal of dichloromethane from waste gases using a biological trickling filter. Bioprocess Eng., 93-99.

5. Gałwa-Widera M., Kwarciak-Kozłowska A., 2016. Ways of eliminating odors in the composting process. Rocznik Ochrony Środowiska, 18.

6. Jorio H., Bibeau L., Viel G., Heitz M. 2000. Effects of gas flow rate and inlet concentration on xylene vapors biofiltration performance. Chemical Engineering Journal,76(3), 209-221.

7. Kapusta K., 2007. Protection of fragranced air quality. World experience in light of the need of legal regulations in Poland, Scientific Work GIG, 4, 31-50.

8. Kośmider J., Mazur-Chrzanowska B., Wyszyński B. 2002. Odours. Wyd. Nauk. PWN, Warszawa.

9. Kwarciak-Kozłowska A. Bańka B. 2014. Biofiltration as a method of neutralization of odors generated during composting of biodegradable fraction of municipal and industrial waste, Engineering and Environmental Protection, 17(4), 631-645.

10. McNevin D., Barford J., 2000. Biofiltration as an odour abatement strategy, Biochemical Engineering Journal, 5(3), 231-242.

11. Pawlaczyk-Szpilowa M. Microbiology of water and sewage. PWN, Warszawa, 1980.

12. Ramirez A., Garcia-Aguilar B., Jones P., Heitz M., 2012. Improvement of methane biofiltration by the addition of non-ionic surfactants to biofilters packed with inert materials, Pro-cess Biochemistry, 47(1), 76-82.

13. Regulation of the Minister of the Environment of 24 August 2012 on the levels of certain substances in the air, OJ. from 18 September 2012, item 1031, Warsaw 2012. 
14. Sówka I., 2011. Methods of identification of odorogenic gases emitted from industrial facilities, publishing house of the Wrocław University of Technology, monograph, Wrocław.

15. Szklarczyk M. 1991. Biological purification of waste gases. Ed. Wroclaw University of Technology, Monografia, Wrocław.

16. Szklarczyk M., Czemarmazowicz M. 1996. Materials of the 4th National Symposium on "Protection of Air in Industry". Lodz University of Technology, Łódź, 27-29 May.

17. Szynkowska M. I., Zwożdzak J., 2010.Contemporary problems of odors, Scientific and Technical Publishers, Warsaw.

18. Twardowski T., Michalska A. 2000. Dilemmas of modern biotechnology from the perspective of biotechnologist and lawyer. Ed. Organizer's House, Torun.
19. Ulfik K., 2010. Biofiltration of volatile organic compounds by means of bacteria and microscopic fungi, Contemporary odor problems, ed. I.M. Szynkowska and J. Zwoździak, Scientific and Technical Publishers, Warsaw.

20. Warych J. 1998. Purification of gases. Processes and apparatus. WNT, Warsaw.

21. Wierzbińska M., 2010. Application of biofiltration methods for deodorization of waste gases using fibrous deposits. part. II - Factors determining the optimization of the biofiltration process. Air protection and waste problems.

22. Wierzbińska M, Modzelewski W.E. 2015. The use of biofilters for deodorising onerous gases. Inżynieria Ekologiczna, 41, 125-132.

23. Van Groenestijn J.W. Kraakman N.J.R., 2005. Recent developments in biological waste gas purification in Europe, Chemical Engineering Journal, 113, 85-91. 